\title{
Shortened REM Latency PostECT Is Associated with Rapid Recurrence of Depressive Symptomatology
}

\author{
Leon Grunhaus, James E. Shipley, Alan Eiser, Atul C. Pande, Rajiv Tandon, \\ Anna Remen, and John F. Greden
}

\begin{abstract}
Electroconvulsive therapy $(E C T)$ is highly effective in the treatment of major depressive disorder $(M D D)$. The l-year relapse rates are reported to be high and in the $30 \%-60 \%$ range, however. To test whether polysomnography (PS) can identify patients with a propensity for relapse we studied 20 patients, responders to a course of ECT, with PS studies. All patients met baseline diagnostic criteria for MDD, were treated with ECT following standardized protocols, had PS studies performed after the course of ECT in a medication-free state, received maintenance antidepressants postECT, and were followed periodically with phone interviews. The recurrence of depressive symptoms was determined at 3 months and 6 months after discharge. Fifty-five percent of the patients were symptomatic when evaluated 6 months after the ECT. Sleep Onset rapid eye movement (REM) periods were identified in 55\% of the patients. As a group, patients who had experienced a recurrence of depressive symptoms by 6 months after discharge, had significantly shorter REM latencies after the course of ECT. A shorter REM latency after ECT identified patients who at six months demonstrated significant depressive symptomatology. Shortened REM latency after ECT in patients with MDD appears to be a correlate of vulnerability for relapse.
\end{abstract}

Key Words: ECT, Mninr depression, sleep studies, REM latency, outcome, MDD

\section{Introduction}

Preventing repeat episodes of Major Depressive Disorder (MDD) is one of the most relevant topics in clinical psychiatry today. Recent studies suggest that a significant proportion of patients with MDD suffer from recurrent episodes, residual symptomatology, or commit suicide (Kiloh et al From the Depanment of Psychiatry. University of Michigan Medical Center, Ann
Atbor, Ml.

Dr. James E. Shipley is now with HRPI, Neuroscience Strategic Business Unit, Somerville. NJ; Dr. Arul C. Pande is now with Lilly Research Laboratories Indianapolis, IN. Address reprint requests to Leon Grunhaus, MD, Department of Psychiatry, Sheba
Medical Center, Tel Hashomer, Israel.

Received August 23, 1993 ; revised January 12, 1994.
1988; Wells et al 1989). The reasons for this malignant course are far from being understood. Insufficient use of antidepressant treatment (Keller et al 1992) or their use for inadequate lengths of time most certainly plays a prominent role in this poor prognosis (Kupfer et al 1992; Kupfer 1992). Factors related to the pathogenesis of the disorder are probably of major relevance to this complicated prognosis, however.

A similar proctrated course of illness has been described for patients with MDD treated with electroconvulsive therapy (ECT). Despite very high rates of response during the acute episode of illness, as high as 70\%-90\% (APA 1990; Abrams 1992), the 1-to-2-year relapse rates following ECT 
may be in the range of 50\% (Spiker et al 1985; Aronson et al 1987; Abou-Saleh and Coppen 1988; Sackeim et al 1990; Winokur et al 1990; Sackeim et al 1993). This seems to be particularly true if the MDD has been treatment resistant or delusional in nature. These high relapse rates are not just a consequence of insufficient treatment and appear related to the pathogenesis of the disorder.

It is self-evident that the identification of specific factors, which may play a role in the outcome of mood disorders is of particular importance in MDD, and in MDD treated with ECT in particular. Such factors could be studied with regard to diagnosis, severity of illness, response to treatment, and longitudinal course. Polysomnography (PS) has been extensively studied in MDD and more recently also in MDD patients treated with ECT (Grunhaus et al 1985, 1988; Hoffmann et al 1985; Coffey et al 1988; Grunhaus et al unpublished data). Although there are questions regarding the specificity of the PS findings in MDD, patients with MDD and particularly patients referred for ECT, demonstrate PS abnormalities most often (Benca et al 1992) (Grunhaus et al unpublished data). From the various PS abnormalities described, very short rapid eye movement (REM) latency appears to be most characteristic of severe depressives (Reynolds et al 1982, 1985, 1991; Thase et al 1986). Sleep onset REM periods (SOREM), a particularly severe form of shortened REM latency, was described in 17 of 25 patients referred for ECT (Grunhaus et al submitted). Interestingly, 10 of these patients continued to demonstrate SOREM after the course of ECT.

Shortened REM latency during baseline PS recordings in patients with MDD appears to be of prognostic significance. Giles et al (1987) and Reynolds et al (1989) have reported that in MDD patients treated successfully with antidepressant medications, reduced REM latency in baseline studies was associated with increased incidence of recurrence. To test whether shortened REM latency in patients treated with ECT is associated with eariy recurrence of depressive symptomatology, we followed 20 patients who had been successfully treated with ECT and who had PS studies recorded postECT.

It is more common to perform PS studies before active treatment is started. Seriously ill patients have great difficulty remaining medication-free for the period necessary to perform sleep studies, however. Performing PS while on psychotropic medications would not have been productive due to the major effects these medications have on PS (Kupfer et al 1989, 1991; Reynolds et al 1989). We therefore use the period of administration of ECT to both improve the clinical condition of the patients and to withdraw all psychotropic medications for at least 10 days before the PS. This methodological change permitted both the inclusion of larger numbers of patients and exploring the relationship of postECT PS findings with clinical outcome.
Patients with recurring depressive symptomatology demonstrated shortened REM latency postECT significantly more often than patients remaining well.

\section{Methods and Materials}

To be included in this study patients were required to have a baseline 17-item Hamilton Rating Scale for Depression (HRSD) score (Hamilton 1960) $\geqslant 18$, to have responded to the course of ECT, and to have had PS studies performed postECT. Patients were considered to be responders to ECT if they maintained an HRSD score $\leq 10$ and a Global Assessment Scale (GAS) $\geqslant 70$ for at least 1 week after the course of ECT.

Twenty consecutive patients ( 6 men and 14 women) responders to a course of ECT and who met our inclusion criteria participated in this study. All subjects were inpatients of the Psychiatry Department of the University of Michigan Hospital. The baseline clinical evaluation included several interviews with senior clinicians, a comprehensive physical and laboratory work-up, interviews with family members whenever available, and a consensus diagnosis whereby at least two clinicians met to ascertain the presence of the Research Diagnostic Criteria (RDC) (Spitzer et al 1978) for MDD. All patients met diagnostic criteria for MDD, 12 of them were endogenous, 11 of them were psychotic, and three were bipolar. No patient who had been treated with ECT in the previous 6 months was included in the study.

Patients were rated weekly with the 17-item HRSD. HRSDs were collected by trained staff supervised by the senior investigator in this project (LG). To define response we used HRSD scores obtained within 1 week of the offset of the ECT course. The mean HRSD score preECT was 26.7 \pm 5.3 with a range of 19 to 39 , whereas mean postECT HRSD score was $3.8 \pm 2.3$ with a range of 0 to 8 . The mean number of previous episodes was $2.8 \pm 2.3$, and the mean age of the first episode of MDD was $52.2 \pm$ 17.7. Age ranged from 37 to 85 years with a mean of $62.3 \pm 13.6$. Demographic and descriptive variables are presented in Table 1.

\section{ECT Procedure}

ECT was performed according to the guidelines of the American Psychiatric Association (1978, 1990). Referral for ECT was made by the attending physician based on clinical criteria. All patients received an extensive preECT workup that included a complete physical and laboratory examination, chest x-rays, electrocardiogram, and consultations with an anesthesiologist for all patients, and a cardiologist for those patients with preexisting cardiac pathology or who were over the age of 50 . Patients included in this study were all American Society for Anesthesia risk I, II, or 
Table 1. Demographic and Clinical Variables

\begin{tabular}{|c|c|c|c|c|c|c|c|c|c|c|}
\hline \multirow[b]{2}{*}{ Patient } & \multirow[b]{2}{*}{ Diagnosis" } & \multirow[b]{2}{*}{ Gender } & \multirow[b]{2}{*}{ Age } & \multirow{2}{*}{$\begin{array}{l}\text { Age of } \\
\text { onset }\end{array}$} & \multirow{2}{*}{$\begin{array}{l}\text { Number of } \\
\text { episodes }\end{array}$} & \multirow[b]{2}{*}{ Psychosis } & \multirow{2}{*}{$\begin{array}{c}\text { Post ECT } \\
\text { REM Latency }\end{array}$} & \multicolumn{2}{|c|}{ HIRSD } & \multirow{2}{*}{$\begin{array}{l}\text { Relapse at } \\
6 \text { monthse }\end{array}$} \\
\hline & & & & & & & & PreECT & Post ECT & \\
\hline 1 & MDD-ED & $\mathbf{M}$ & 69 & 67 & 1 & yes & 1 & 27 & 8 & yes \\
\hline 2 & MDD-ED & $\mathbf{F}$ & 80 & 40 & 4 & yes & 10 & 19 & 1 & yes \\
\hline 3 & MDD-ED & $\mathbf{F}$ & 54 & 54 & 1 & yes & 83.5 & 39 & 6 & no \\
\hline 4 & MDD & $\mathbf{F}$ & 73 & 67 & 3 & no & 16.5 & 25 & 5 & yes \\
\hline 5 & MDD-ED & $\mathbf{F}$ & 37 & 20 & 4 & no & 41.5 & 27 & 2 & no \\
\hline 6 & MDD & $\mathbf{F}$ & 41 & 10 & 6 & no & 11.5 & 21 & 3 & yes \\
\hline 7 & MDD-ED & $\mathbf{F}$ & 69 & - & - & yes & 0 & 26 & 5 & no \\
\hline 8 & MDD-ED & $\mathbf{F}$ & 51 & 29 & 10 & yes & 0 & 30 & 6 & yes \\
\hline 9 & MDD-ED & $\mathbf{F}$ & 53 & 51 & 2 & no & 96 & 26 & 1 & no \\
\hline 10 & MDD-ED & $\mathbf{M}$ & 75 & 65 & 1 & yes & 150 & 30 & 1 & no \\
\hline 11 & MDD-ED & $\mathbf{F}$ & 64 & 49 & 7 & no & 25 & 28 & 6 & yes \\
\hline 12 & MDD-ED & $\mathbf{F}$ & 72 & 72 & 1 & yes & 5 & 31 & 2 & no \\
\hline 13 & MDD-ED & $\mathbf{F}$ & 53 & 39 & 4 & no & 67 & 18 & 4 & yes \\
\hline 14 & MDD-ED & $\mathbf{F}$ & 70 & 56 & 3 & no & 67 & 26 & 7 & no \\
\hline 15 & MDD-ED & $\mathbf{M}$ & 68 & 66 & 1 & yes & 6.5 & 37 & 3 & no \\
\hline 16 & MDD-ED & $\mathbf{M}$ & 67 & 66 & 1 & yes & 8 & 28 & 4 & yes \\
\hline 17 & MDD-ED & $\mathbf{M}$ & 61 & 61 & 1 & yes & 0 & 21 & 5 & yes \\
\hline 18 & MDD & $\mathbf{F}$ & 37 & 36 & I & no & S5 & 22 & 5 & yes \\
\hline 19 & MDD-ED & $\mathbf{F}$ & 85 & 64 & 3 & yes & 169 & 29 & 1 & no \\
\hline 20 & MDD-ED & $\mathbf{M}$ & 66 & 63 & 3 & no & 0 & 25 & 0 & yes \\
\hline Means \pm & SD: & F: $14 M: 6$ & $62.3 \pm 13.6$ & $52.2 \pm 17.7$ & $2.8 \pm 2.3$ & $Y: 11$ N: 9 & $40.6 \pm 50.9$ & $26.7 \pm 5.3$ & $3.8 \pm 2.3$ & Y: 11/N: 9 \\
\hline
\end{tabular}

MDD = major depressive disonder, ED = endogenous, HRSD = Hamilton Rating Scale for Depression, 17-item.

ARDC diagnosis.

-REM latency recorded in minutes.

"Relapse" defined by a Global Assessment Scale score $\leq 55$.

III. All patients signed a written consent for ECT. A standardized method for obtaining consent including the viewing of an educational videotape on ECT (Grunhaus and Barroso-Wahl 1988), the reading of a booklet on ECT (Grunhaus and Barroso-Wahl 1989) and discussions about ECT with a dedicated ECT nurse and the treating psychiatrist was used. ECT was performed between 8 and $10 \mathrm{AM}$ in a specialized ECT suite. All patients were observed in the recovery area until judged sufficiently awake for transport to their unit. Anticholinergic medications were not prescribed preECT. The administration of anticholinergic me cations, especially in elderly patients, is associated with higher baseline pulse and higher peak pulses during ECT. Thus, the potential negative effects in populations at risk outweigh the potential benefits (Bouckoms et al 1989). Although we used a modified seizure threshold titration method (Sackeim et al 1987) and occasionally administered subconvuisive electrical stimulus, no untoward cardiovascular effects were observed. The only medications allowed during the ECT course were cardiac or antireflux medications. Methohexital $(0.75 \mathrm{mg} / \mathrm{kg})$, succinylcholine (1 $\mathrm{mg} / \mathrm{kg}$ ), and constant $100 \%$ oxygen through a face mask were administered in all treatments. Short acting betablocking agents (labetalol and esmolol) were used as necessary for cardiovascular stabilization. Midazolam, a short acting benzodiazepine, was used occasionally for signifi- cant postECT agitation; in all cases the last dose of midazolam was administered at least 10 days before the postF.CT SP. The equipment used for the administration of the ECT included a Mecta SR1 and SR2 machines which deliver a bidirectional quadratic brief-pulse stimulus. The choice of electrode placement and the switch from unilateral to bilateral placement was not controlled for the purposes of this study and was left for the clinician administering ECT to decide. Eight patients received unilateral ECTs and 12 patients received bilateral ECT. Electrical parameters were determined using a modified scizure threshold titration method (Sackeim et al 1987). Seizure threshold was determined during the first ECT treatment. For the following treatment, energy parameters were set to deliver $150 \%$ of the initial charge. During the remainder of the ECT course, energy parameters were increased by one or two seitings every third or fourth treatment. Length of seizure was monitored by two clinicians with the cuff-method and restimulation at higher energy parameters was performed if the seizure lasted $<25 \mathrm{sec}$. The mean seizure duration (arrived at by dividing the total seizure seconds by the number of treatments) was $39.2 \pm 12.9 \mathrm{sec}$. The length of the ECT treatment was not standardized and the ECT course was terminated after the attending physician treating the patient considered improvement sufficient or that no further benefits from ECT could be expected. The mean number of 


\section{ECT's was $7.7 \pm 2.5$.}

\section{PS Procedures}

All patients were on psychotropic medication preECT. Within days of starting the ECT course medications were tapered, however. Patients had been free of psychotropic medication, with the exception of the short-acting barbiturates and muscle relaxants administered during ECT, for at least 10 days before the postECT PS studies. PS studies were performed no sooner than $24 \mathrm{hr}$ and no later than $96 \mathrm{hr}$ from the last ECT. Performing PS studies postECT permitted the inclusion of patients whose severity of illness at baseline was such that a medication-free observation period was unattainable. This methodological change allows performing studies over shorter periods of time. As an example, for our previous study of PS studies preECT and postECT (Grunhaus et al unpublished data) it took over 5 years to collect a sample of 25 patients. The sample we are currently reporting on, postECT PS studies on ECT responders, was collected over a period of 14 months.

Daytime naps during the PS studies days were not permitted. PS tracings were recorded and scored by technicians blind to the fact that patients were receiving ECT. Clinicians performing clinical ratings were kept blind to PS results. Patients were recorded from their hospital beds, all of which were directly wired to the sleep laboratory control room. Recordings were done using a Telefactor (West Conshohocken, PA) encoder-decoder system and recorded on a Grass model 78 polygraph, with a resulting nominal EEG band pass of 0.3-30 Hz. For all subjects electrode impedance's were less than 5,000 ohms and paper speed was $10 \mathrm{~mm} / \mathrm{sec}$.

On the first night of study a full montage polysomnogram was used to rule out primary sleep disorders such as sleep apnea or nocturnal myoclonus. This included electroencephalogram (EEG) (C3/A2), referential electrooculogram (EOG), submental electromyogrant (EMG), respiratory monitoring (nasal-oral thermistors, abdominal and chest strain gauges, and ear oximetry), electrocardiogram, and EMG of the anterior tibialis muscle. On the subsequent night, information required for sleep staging was recorded (EEG, EOG, and chin EMG). Patients having primary sleep disorders were excluded from the study and no additional information was recorded.

All polygraph records were scored visually using a 60 sec epoch according to modified Rechtshaffen and Kale's criteria (Rechtschaffen et al 1968). The visually scored EEG sleep variables were divided into three groups: sleep continuity, sleep architecture, and REM sleep indices. (1) sleep continuity indices: total recording period (TRP); time spent asleep (TSA) = net sleep time; sleep efficiency (TSA/TRP X 100); sleep latency (time from the beginning of the recording until the onset of stage 2 sleep for at least $10 \mathrm{~min}$ interrupted by no more than 2 min of stage 1 , or one minute of stage 1 plus one minute of wakefulness); sleep maintenance (percentage of time asleep during the total recording period after sleep latency), wakefulness after sleep onset (time spent awake during the night which is bounded by sleep); and wakefulness during the last 2 hr of the recording. (2) Sleep architecture indices: percentages of net sleep time spent in stages 1,2,3,4, and delta; and REM. (3) REM sleep indices: REM time (RT); REM activity (RA, an integrative measure of the frequency of rapid eye movements scored by visual inspection on a scale of 0-8 per min of REM sleep); REM density (RA/RT); REM sleep latency (the time between sleep onset and the first REM period). A REM period was defined as a minimum of $3 \mathrm{~min}$ of REM sleep within 30 min of each other. Patients were considered as having a sleep onset REM period (SOREM) period when the average of both nights of REM latency was less than $20 \mathrm{~min}$.

\section{Follow-Up Period}

Maintenance pharmacotherapy was initiated in all cases following the last night of PS recording. Antidepressant regimen was chosen by the clinician in charge of the case. The antidepressants prescribed included: fluoxetine, nortriptyline, and desipramine. Patients were discharged with the recommendation to achieve a therapeutic dose within 1 week of discharge. At 3 and 6 months after discharge patients were contacted by one of the investigators. The follow-up protocol was approved by the institutional review board and patients consented to the phone interview. This phone interview lasted approximately $30 \mathrm{~min}$ and included questions concerning clinical outcome, medication regimen, and compliance. The pharmacological treatment was assessed with the Michigan Adequacy of Treatment Scale (MATS) (Grunhaus and Remen 1993). This scale rates the adequacy of antidepressant treatment on a one-to-five score, one being insufficient treatment and five being the highest level of treatment recommended for a particular antidepressant medication (i.e., fluoxetine $80 \mathrm{mg} /$ day). All patients were required to have at least a level two for inclusion in the study. Level two represents 50-75 $\mathrm{mg}$ a day of nortriptyline, $20-39 \mathrm{mg}$ a day of fluoxetine, or $100-150 \mathrm{mg}$ a day of desipramine.

The clinical condition was assessed with a standardized set of questions aimed at obtaining a GAS score. We chose to evaluate patients with the GAS to assess not just signs of relapse but also dysfunctional states which have been reported as being quite common in MDD patients (Wells et al 1989). We classified patients into tho: remairing well (GAS $\geqslant 70$ ), those having residual symptomarology (GAS in the range of 50-69) and not meeting $R D C$ criteria for MDD, and those having had a recurrence or relapse (GAS < 50) and meeting RDC criteria for MDD. 


\section{DataAnalysis}

Logarithmic transformation was performed on those variables with significant skewness and kurtosis. Patients were grouped into two categories based on the GAS scores; the "remaining well" group were those with a GAS $\geqslant 70$ and the "symptomatic" group were those who demonstrated recurrence of depressive and dysfunctional symptoms (GAS S 69). Patients in the "residual" and "relapse" groups were compared on a number of core variables, like REM latency and presence of SOREM, and found not to be different. Therefore, these groups were collapsed into one category, the "symptomatic" category, for data analysis. Comparisons were based on the results from the 6-month follow-up interview.

Analyses included $t$-tests for continuous data, and $x^{2}$ for categorical data. Results from the two nights of sleep recordings were averaged for data analysis. To test whether certain clinical or PS variables were associated with the recurrence of symptoms, we performed several logistic regressions where the independent variable was the parameter of interest and the dependent variable the group outcome. The relatively small sample size did not allow including the variables in one analysis, therefore we performed separate analysis for age, age of onset, number of episodes, REM latency, REM density, EMA, and \%SE. Statistical analysis was performed on a Macintosh SE/30 computer using the Statview II statistical package (Statview 1985) and the JMP program (SAS Institute Inc 1989).

\section{Results}

Only nine patients (45\%) remained well 6 months after the ECT course. Seven $(35 \%)$ of the remaining 11 patients had relapsed, and 4 (20\%) demonstrated significant depressive symptoms but did not meet full diagnostic criteria for MDD. As mentioned previously the latter two categories were grouped together for data analysis.

We compared "remaining well" patients with "symptomatic" patients on a number of clinical variables; these included: age of onset, preECT and postECT HRSD score, number of ECT's, mean seizure duration (total seizure time $\mathrm{d}$ by the number of treatments), presence of psychosis, and level of MATS treatment preECT and during follow-up. Of these, only the preECT HRSD was significantly different between the groups with patients in the "symptomatic" category having lower preECT scores than patients in the "remaining well" category ( $24 \pm 4.0$ versus $30.1 \pm$ $4.9, t=3.1, p=\leq 0.01$ ). No age difference was identified between the "remaining well" and "symptomatic" categories $(60.2 \pm 13.3$ versus $64.8 \pm 14.4, \mathrm{NS})$.

The PS parameters of sleep continuity, sleep architecture, and REM were also analyzed for the 6-month time point. REM latency was the only variable differentiating between the groups, with patients in the "symptomatic" category demonstrating significantly shorter REM latencies (17.6 \pm 23 versus $68.7 \pm 62.3, t=2.5, p=0.02$ ). Eleven (55\%) patients had SOREM after the treatment. (See Figure 1).

The logistic regression demonstrated that shorter REM latency occurs significantly more often in symptomatic patients (analysis of $\log L i k e l i h o o d, C$ total 13.8, $X^{2}=6.1, p=$ 0.01 ). The regression line demonstrated that a $R E M$ latency of $\leq 20$ min was associated with a $67 \%$ chance of being symptomatic by 6 months after the ECT course. (See Figure 2).

\section{Discussion}

This study was designed to test whether sleep variables, and particularly shortened REM latency, have value in the prediction of relapse of depressive symptomatology. Patients included in this study had to meet three requirements: to have responded to the course of ECT, to have had PS studies performed after ECT, and to have remained in follow-up taking adequate maintenance pharmacotherapy for 6 months after the ECT's. REM latency was the one sleep variable that differentiated between symptomatic and remaining well patients. Shortened REM latency postECT was associated with the recurrence of depressive symptomatology, as demonstrated both by mean group values and by logistic regression. As a group, patients who were symptomatic at follow-up had significantly shorter REM latency postECT than patients remaining well $(p=0.02)$. A shortened REM latency postECT identified patients who later became symptomatic $(p=0.01)$. This was especially true for REM latencies $\leq 20 \mathrm{~min}$ (SOREM). The regression curve suggests that patients with SOREM postECT had close to a $70 \%$ chance of being symptomatic 6 months after ECT. Shortened REM latency was evident and equally low, both in patients who had fully relapsed and in those who demonstrated significant symptomatology but did not meet criteria for a full depressive relapse. These findings suggest that shortened REM latency postECT (and particularly the presence of SOREM periods), is a vulnerability factor in MDD and predictive of an ominous course of illness.

Further support for the proposal that shortened REM latency is a vulnerability factor in MDD and is frequently associated with relapse, comes from the reports by Giles et al (1987) and Reynolds et al (1989). Giles et al followed 25 patients with MDD who responded to antidepressant treatment either in the form of medication or cognitive therapy. The authors found that during the follow-up period those patients who had shorter REM latency ( $\leqslant 65 \mathrm{~min}$ ) during baseline studies, relapsed more frequently and sooner than patients with longer REM latencies (>65 min). By the 12-month of follow-up, the cumulative likelihood of recurrence in the group with longer latency was $20 \%$, whereas in 


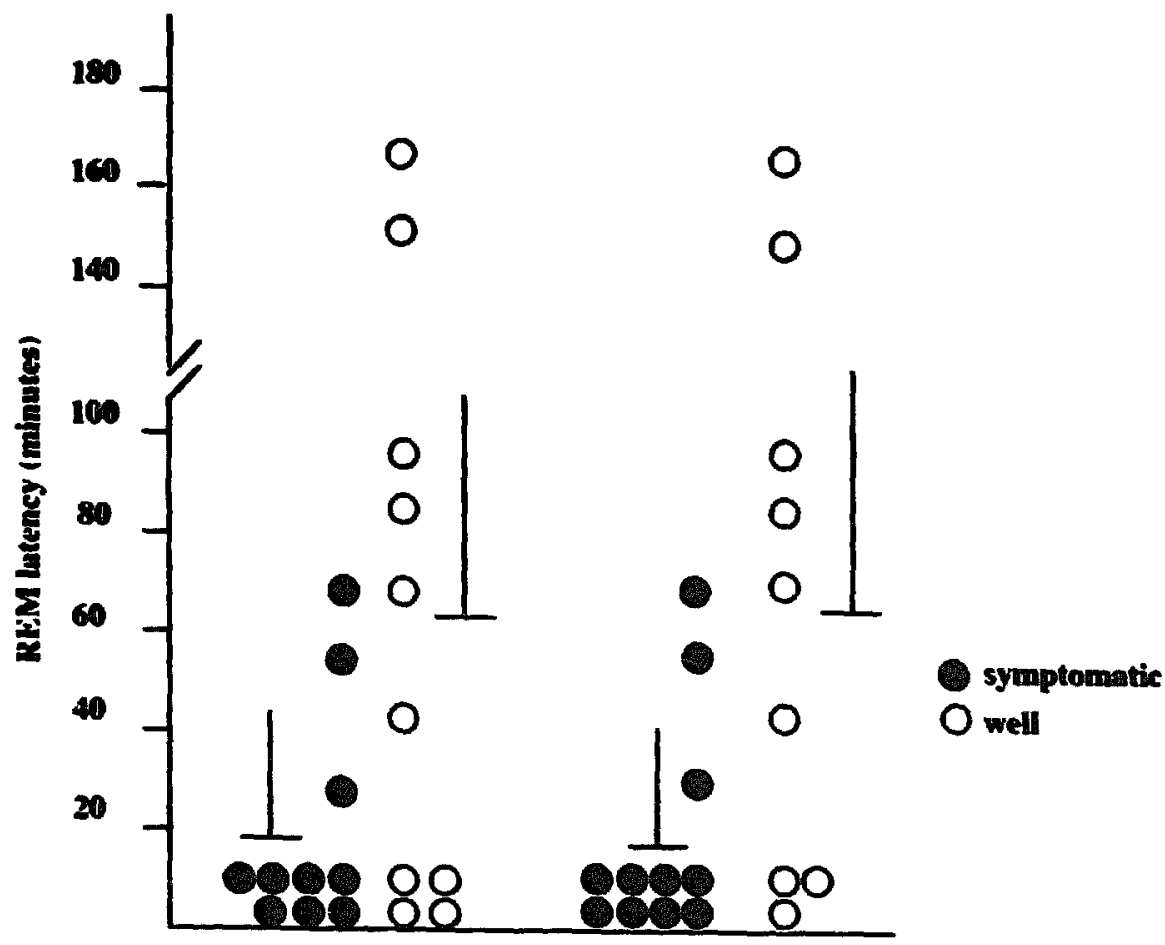

Figure 1. REM latency postECT according to the "symptomatic" and "remaining well" categories. Results are presented for both the 3 and 6 months follow-up observacions.

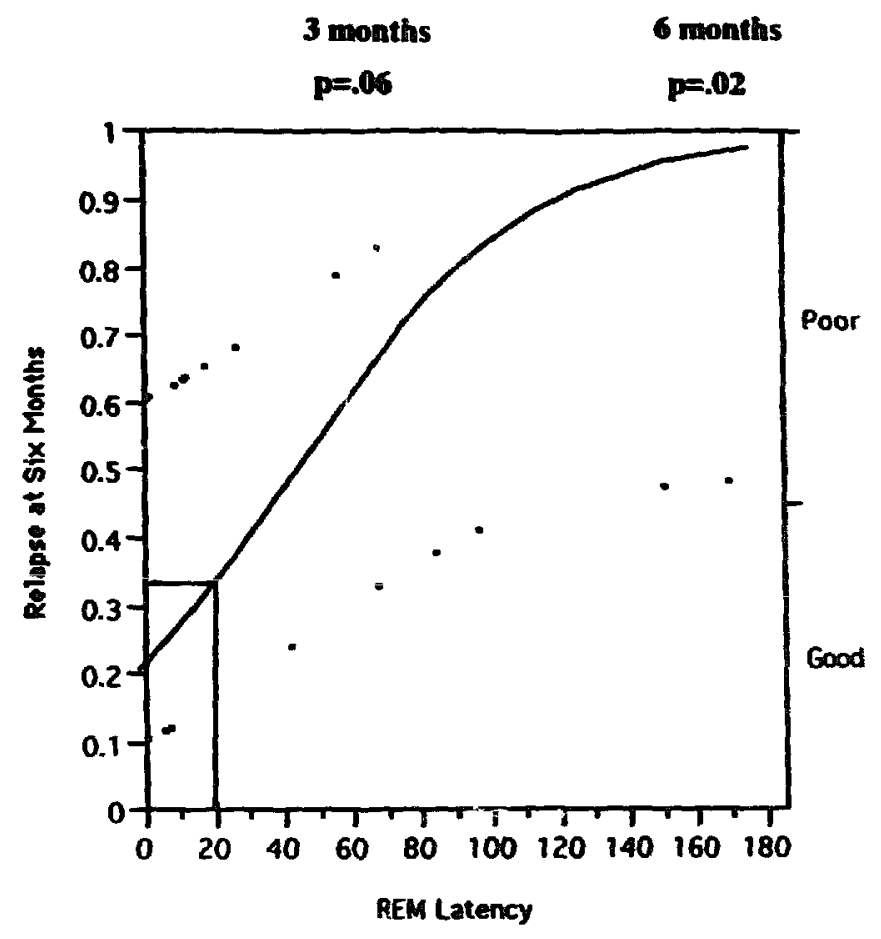

Figure 2. Results of the Jogistic regression analysis exploring the value of shorter REM latencies in predicting the "remaining well" and "symptomatic" groups. Due to limitations of the computer program categories were renamed "good" and poor." The results of the analysis of loglikelihood $\left(x^{2}=6.09, p=0.01\right)$ suggest that shorter REM latencies are associated with a greater propensity for relapse. The predictive value of a REM latency $\leq 20$ is highlighted. the group with shorter latency the likelinusud was approximately $65 \%$. These authors concluded that REM latency could represent both a trait marker and a vulnerability factor in MDD. Reynolds et al reported on 27 geriatric patients with MDD treated with nortriptyline. The four patients that relapsed during the follow-up, all had had shorter REM latency at baseline (mean pretreatment REM latency of $18.4 \pm 7.4$ ).

Short REM latency in MDD has been traditionally viewed as a state marker of acuity, one that should revert to normal with recovery. More recent studies, including ours, have found shortened REM latency persisting even after several months of recovery (Hauri et al 1974; Puig-Antich et al 1983; Giles et al 1987). The pathogenic relevance of shortened REM latency is therefore unclear. Is it a state marker of MDD? Is it a consequence of depression that remits more slowly? Is it an indicator of continued vulnerability? and/or is it a potential predictor of depression for people who are unaffected but at risk? (Reynolds et al 1987). The studies by Giles et ai. Reynolds et al, and ours provide strong support for the hypothesis that shortened REM latency in MDD is an indicator sf continued vulnerability.

Other sleep abnormalities persisting well into the recov- 
ery periods have been described (Hauri et al 1974; PuigAntich et al 1983; Rush et al 1986). Only a computerized measure of delta waves has been reported to predict relapse in patients with MDD Kupfer et al 1990), however. Patients with a reduced delta count ratio between the first and second REM periods were found to relapse more rapidly (during a phase with no medication) than patients with high delta ratios. In our study no other sleep variable was found to differentiate beiween the groups. The measurement of delta counts, which requires computerized readings of the SP was not performed.

Of interest is the fact that in the studies of Giles et al (1987) and Kupfer et al (1990), patients were maintained on medications for a standardized period of time, and it was only after withdrawal of the medications that relapse occurred. In our study, recurrence of symptoms occurred much sooner and while patients were receiving antidepressant treatment. Patients in our study reportedly had a very high proportion of SOREM periods. It is possible then, that shorter REM latencies and particularly SOREM periods reflect a more profound neurobiological abnormality, one that is reflected both in clinical severity and in rapid relapse.

The high incidence of SOREM periods in ECT-treated patients is quite remarkable. In this sample, $55 \%$ of the patients demonstrated SOREM postECT. In a previous study from our group we found preECT SOREM periods in over $70 \%$ of the MDD patients (Grunhaus et al unpublished data). Thase et al and Kupfer et al (1986; Thase et al 1986) have reported that some $50 \%$ of patients with delusional MDD have SOREM periods. In our sample approximately half of the patients were delusional and most of them had SOREM (see Table 1). Very short REM latencies may reflect neurophysiological and neurochemical imbalances associated with this form of severe depression. Post (Post et al 1986; Post 1992a, 1992b) has recently advanced a comprehensive hypothesis exploring the interactions between environmental events, molecular biology changes and affective illness. According to this hypothesis, recurrent episodes, and possibly severe, protracted or refractory episodes of affective illness, impact gene expression in such a way that changes tuduced by the illness are incorporated, possibly as "memory" traces, and have the potential for mediating vulnerability to recurrence in a long-lasting fashion. The persistence of these neurobiological alterations after recovery of the clinical syndrome may be associated with a vulnerability for relapse (Post 1992). To hypothesize that the neurobiological changes proposed by Post are the forerunners of SOREM and relapse in our patients would be highly speculative at this point. Consideration of this possibility reinforces the need for long-term prophylaxis in these patients, however.

Sorne comments concerning our methods are needed: (1) Regarding the sample size. This report is based on a small sample size, thus the conclusions need to be considered preliminary. This report was written to encourage authors treating this very sick population to address the issue of sleep and recovery after treatment with ECT. (2) On the timing of the PS studies, as mentioned, performing SP studies only after the course of ECT is less common. We decided on this approach for the following two reasons. First, it allowed us to include a more representative sample of ECTtreated patients. Patients referred for ECT are usually quite ill and cannot tolerate the drug-free period required for PS studies, therefore they are seldomly included in baseline PS studies; collecting a representative sample is, therefore, a lengthy process. And second, it is possible that biological findings obtained posttreatnient more accurately reflect the vulnerability for relapse than baseline studies. (3) Regarding post-ECT clinical care, follow-up was left to clinicians in the community who received extensive recommendations from the research team. Although these were sophisticated clinicians who followed our recommendations very carefully, a closer follow-up by the research team would have provided more accurate information regarding the time to relapse, compliance with treatment, and issues of dosage and type of antidepressant medication. (4) Regarding the effects of age on the results, the effects of age on PS parameters are known to be significant. In the preliminary analysis we performed on this sample, age was not a factor on either clinical outcome at 6 months or REM latency, however. Whether age is less relevant for either PS studies after the recovery from the acute episode or for longitudinal outcome, is a question worthwhile exploring in larger sample. (5) On the effects of ECT on PS parameters, ECT may impact on PS parameters through its antidepressant actions and through other nonspecific neurochemical actions. These nonspecific effects may affect REM parameters in such a way that interpretation of PS results becomes difficult. For example, experiments performed in cats in the late 1960 s demonstrated that electrical convulsions exert marked effects on REM sleep parameters (Cohen and Dement 1966; Kaelbling et al 1968) and lead to reductions in REM time, REM activity, and number of REM periods. Although we cannot separate these two effects of ECT, the presence of shortened REM latency preECT in a high proportion of patients (Grunhaus et al unpubiished data), suggests that our finding of postECT shortened REM latency is related to the underlying diathesis and not to the effects of ECT.

The potential application of the findings we have reported to the study of the pathophysiology of severe depression and for treatment planing in this disorder, could be extensive. For example, determining whether SOREM periods can be modified by an anticholinergic challenge could be used to test the "cholinergic overdrive hypothesis" (Berger et al 1989) of shortened REM latency in MDD. 
Clinically, determining whether patients with shortened REM latency postECT have specific treatment requirements could be instrumental in improving the outcome of this group of patients. It is possible that patients with shortened REM latency require maintenance strategies that may include maintenance ECT or more than one psychotropic agent.

It is evident that additional studies are required before

\section{References}

Abou-Saleh MT, Coppen AJ (1988): Continuation therapy with antidepressants after convulsive therapy. Convulsive Therapy 4:263-268.

Abrams R (1992): Electroconvulsive therapy, 2nd ed. New York: Oxford University Press.

American Psychiatric Association (1978): Task Force Report 14: Electroconvulsive Therapy. Washington, DC: American Psychiatric Press.

American Psychiatric Association (1990): The Practice of Electroconvulsive Therapy. Washington, DC: American Psychiatric Association.

Aronson, TA, Shukla S, Hoff A (1987): Continuation therapy after ECT for delusional depression: A naturalistic study of prophylactic treatments and relapse. Convulsive Therapy 3:251-259.

Benca RM, Obermeyer WH, Thisted RA, Gillin JC ( 1992): Sleep and Psychiatric disorders: A meta-analysis. Arch Gen Psychiatry 49:651-668.

Berger M, Riemann D, Hochli D, Spiegel R (1989): The cholinergic rapid eye movement sleep induction test with RS-86. Arch Gen Psychiatry 46:421-428.

Bouckoms AJ, Welch CA, Drop LJ, Dao T, Kolton K (1989): Atropine in electroconvulsive therapy. Convulsive Therapy 5:48-55.

Coffey CE, McCall WV, Hoelscher J, et al (1988): Effects of ECT on Polysomnographic Sleep: A Prospective Investigation. Convulsive Therapy 4:269-279.

Cohen HB, Dement WC (1966): Sleep: Supression of rapid eye movement phase in the cat after electroconvulsive shock. Science 154:396-398.

Giles DE, Jarret RB, Roffwarg HP, Rush AJ (1987): Reduced rapid eye movement latency. A predictor of recurrence in depression. Neurospychopharmacology 1:33-39.

Grunhaus L, Barroso-Wahl L (1988): ECT: The treatment, the questions, the answers. Ann Arbor: University of Michigan Biomedical Communications.

Grunhaus L, Barroso-Wahl L (1989): ECT: The treatment, the question, the answers. Ann Arbor: University of Michigan Biomedical Communications.

Grunhaus L, Remen A (1993): The Michigan Adequacy of Treatment Scale (M.A.T.S.). J Clin Psychopharmacol.

Grunhaus L, Tiongco D, Pande A, et al (1988): Monitoring of antidepressant response to ECT with polysomnographic recordings and the Dexamethasone Suppression Test. Psychiatry Res 24:177-185.

Grunhaus L, Tiongco D, Roerich H, Eiser A, Feinberg M, Greden JF (1985): Serial monitoring of antidepressant response to definite conclusions regarding the value of shortened REM latency in ECT-treated patients can be drawn. The data we have gathered are relevant in answering the very important question we raised in our introduction, "are there biological correlates of relapse in severe depression?" It appears that shortened REM Jatency postECT may well be one of these correlates.

electroconvulsive therapy with sleep EEG recordings. Biol Psychiatry 20:805-808.

Hamilton M(1960): A Rating scale for depression. J Neurol Neurosurg Psychiatry 23:53-62.

Hauri P, Chemik D, Hawkins P, Mendels J (1974): Sleep of depressed patients in remission. Arch Gen Psychiatry 31:386391.

Hoffmann G. Linkowski P. Kerkhofs M. Desmedt D. Mendlewicz $J$ (1985): Effects of ECT on sleep and CSF biogenic amines in affective illness. Psychiatry Res 16:199-206.

Kaelbling R, Koski EG, Hartwig CD (1986): Reduction of rapideye-movement sleep after electroconvulsions-An experiment in cats on the mode of action of electroconvulsive treatment. $J$ Psychiatr Res 6:153-157.

Keller MB, Lavori PW, Mueller T1, et al (1992): Time to recovery, chronicity, and levels of psychopathology in major depression. Arch Gen Psychiatry 49:809-816.

Kiloh LG, Andrews G, Neilson M (1988): The long-term outcome of depressive illness. Br J Psychiatry 153:752-757.

Kupfer DJ (1992): Maintenance treatment in recurrent depression: Current and future directions. Br J Psychiatry 161:309-316.

Kupfer D\}, Ehlers C (1989): Two roads to rapid eye movement latency. Arch Gen Psychiatry 46:945-948.

Kupfer DJ, Reynolds III ChF, Grochocinski VJ, Ulrich RF, McEachran A (1986): Aspects of short REM latency in affective states: A revisit. Psychiatry Res 17:49-59.

Kupfer DJ, Ehlers CL. Pollock BJ, Nathan RS, Perel JM (1989): Clomipramine and EEG sleep in depression. Psychiatry Res 30:165-180.

Kupfer DI, Frank E, McEachran AB, Grochocinski VJ (1990): Delta sleep ratio: $A$ biological correlate of early recurrence in unipolar affective disorder. Arch Gen Psychiatry 47:11001105.

Kupfer DJ, Perel IM, Pollock BJ, et al (1991): Fluvoxamine vs desipramine: Comparative polysomnographic effects. Biol Psychiatry 29:23-40.

Kupfer DJ, Krank E, Perel JM, et ai (1992): Five-year outcome for maintenance therapies in recurrent depression. Arch Gen Psychiatry 49:769-773.

Post RM (1994): Mechanisms underlying the evolution of affective disorders. In Grunhaus L, Greden JF (eds), Severe Depressive Disorders. Washington, DC: American Psychiatric Press.

Post RM (1992): The transduction of psychosocial stress into the neurobiology of recurrent affective disorder. Am J Psychiatry 149:999-1010.

Post RM, Rubinow DR, Ballenger JC (1986): Conditioning and 
sensitization in the longitudinal course of affective illness. BrJ Pswchiarry 149:191-201.

Puig-Antich J, Goetz R, Hanlon C. Tabrizi MA. Davies M, Weitzman ED (1983): Sleep architecture and REM sleep measures in prepubertal major depression. Arch Gen Psychiaty 40:187192.

Rechtschaffen A, Kales A, Berger RJ (1968): A Manual of Standardized Terminology, Techniques, and Scoring Systems for Sleep Studies in Human Subjects. Washington, DC: US Public Health System.

Reynolds III CF, Kupfer DJ, Taska LS, et al (1985): Sleep of healthy seniors: A revisit. Sleep 8:20-29.

Reynolds III CF, Gillin JC, Kupfer DJ (1987): Sleep and Affective Disorders. In Psychopharmacology: The third Generation of Progress, ed. Meltzer HY. New York: Raven Press, 647-654.

Reynolds III CF. Perei JM, Frank E, Imber S, Kupfer DJ (1989): Open trial maintenance nortriptyline in geriatric depression: Survival analysis and preliminary data on the use of REM latency as a predictor of recurrence. Psychopharmacol Bull 25:129-132.

Reynolds III CF, Kupfer DJ, Taska LS, et al (1982): EEG sleep in elderly depressed, demented, and healthy subjects. Biol Psychiain 20:431-442.

Rush JA, Erman MK, Giles DE, et al (1986): Polysomnographic findings in recently drug-free and clinically remitted depressed patients. Arch Gen Psychiatry 43:878-884.
Sackeim H, Decina P, Prohovnik I, Malitz S (1987): Seizure threshold in electroconvuslive therapy. Arch Gen Psychiatry 44:355-360.

Sackeim HA, Prudic J, Devanand DP, Decina P, Kerr B, Malitz S (1990): The impact of medication resistance and continuation pharmacotherapy on relapse following response to electroconvulsive therapy in major depression. J Clin Psychopharmacol 10:96-104.

Spiker DG, Stein J, Rich CL (1985): Delusional depression and electroconvulsive therapy: One year later. Convulsive Therapy $1: 167-182$.

Spitzer RL, Endicott J, Robins E (1978): Research diagnostic criteria (RDC): Rationale and reliability. Arch Gen Psychiaty 35:773-782.

Siatview (1985): Statview, the graphics statistic utility for the Macintosh. Calabasas, CA: Brain Power.

Thase ME, Kupfer DJ, Ulrich RF (1986): Electroencephalographic sleep in psychotic depression. A valid subtype? Arch Gen Psychiatry 43:886-893.

Wells KB, Stewart A, Hays RD (1989): The functioning and wellbeing of depressed patients. Results from the medical outcomes study. JAMA 262:914-919.

Winokur G, Coryell W, Keller M, Scheftner WA (1990): Relationship of elecroconvulsive therapy to course in affective illness: A collaborative study. Eu Arch Psychiatry Clin Neurosci 240:54-59. 